\title{
Study on Interest Coordination Mechanism of Green Supply Chain Based on Dynamic Game
}

\author{
Lu fu-cai ${ }^{1}$, Chen si-hua $^{2} *$ and He wei ${ }^{3}$ \\ ${ }^{1}$ Institute of Industrial Economics, Jiangxi University of Finance and Economics, \\ No.169, East Shuanggang Road, Changbei, Nanchang, Jiangxi 330046, China \\ ${ }^{2}$ School of Information Technology, Jiangxi University of Finance and Economics, \\ No.169, East Shuanggang Road, Changbei, Nanchang, Jiangxi 330046, China \\ doriancsh@foxmail.com \\ ${ }^{3}$ School of Business and administration, Jiangxi University of Finance And \\ Economics, No.169, East Shuanggang Road, Changbei, Nanchang, Jiangxi \\ 330013, China
}

\begin{abstract}
Green supply chain which aims at utilizing industrial waste is an effective form of circular economy and practical response to Chinese government's call for establishment of conservation-oriented society. However, how to coordinate interests of members in green supply chain is a tricky but key problem for the smooth operation of green supply chain. Based on a multi-stage dynamic game model of green supply chain, this paper explores the interest relationship between government and manufacturers, that among manufacturers and that between manufacturers and retailers. Furthermore, this paper proposes measures and conditions to ensure effective operation of green supply chain and intends to offer references for product pricing of green supply chain, coordination of members of green supply chain as well as governmental environment policy formulation.
\end{abstract}

Keywords: Green supply chain, Game, Interest coordination

\section{Introduction}

With the increase of environmental disposal cost of waste and increase of material purchasing cost, recently lots of attentions have been paid to green supply chain, a cooperation mode of core industrial waste (usually including by-products, symbiotic products and residues)manufacturers of supply chain [1]. Industrial waste production has its own special features. It exists both as environmental loads of upstream suppliers and as raw material of downstream customers. In addition, the production of industrial waste mainly depends on market demand of main products and therefore production of industrial waste is limited. All these features of industrial waste different from common products lead to the particularity of cooperation of green supply chain. To realize coordination of green supply chain, industrial waste pricing is one of the key problems to tackle. Therefore, designing a sound pricing strategy to optimize operation and environmental performance of green supply chain has special significance. Green supply chain is comprised of different types of members and they are independent from each other. If members of green supply chain separately make decisions and maximize their own interests, there will be problem of double marginalization and the overall optimization of supply chain is hard to obtain. Therefore, it is necessary to guide members of green supply chain to cooperate by sharing information and gains, establishing technology alliances to realize win-win.

Green et al. considered organizational consumption in the context of supply chains, with respect to the issue of agency within the organization and with respect to the 
transmissions of market signals for innovation [2]. The discussion made clear the importance of considering the inter-organizational context and ways in which this context both constrained and enabled green purchasing initiatives. Based on case studies in the British and Japanese food retail sector and the British aerospace industry, Hall found that environmental supply chain dynamics (ESCD) emerged if there was a channel leader with sufficient channel power over their suppliers, technical competencies, and were themselves under specific environmental pressure [3]. Li Xin-ran and Li Guang-peng proved that it was inevitable to green the supply chain through mutual cooperation from the aspect of game theory [4]. They stated the social value of green supply chain from viewpoint of demand-supply perspective and analyzed the profits which green supply chain brought to the corporation through their cooperation. Based on a two-stage game theory, Zhang Ping and Wu Chun-xu developed a model of selection and estimation of partner in green supply chain by combining AHP and the Integer Programming [5]. Jiao Xu-ping et al. compared the different system efficiencies in cooperative and noncooperative games in the setting of a market where the common and green products coexist [6]. The result showed the cooperation between suppliers and manufacturers can achieve win-win. Furthermore, the Rubinstein bargaining model was used to analyze the best price-making decision and the best feasible Pareto price-making strategy was proposed. Using the data from a survey of the Canadian and United States package printing industry, the linkage between green project partnership and five performance indicators was tested by Vachon and Klassen [7]. The results indicated that green project partnership with customers was positively linked to quality, flexibility and environmental performance while partnership with suppliers was associated with better delivery performance. Wang Neng-ming and Yang Tong studied the coordination mechanism of members in green supply chain [8]. They pointed out the cooperation among suppliers, manufacturers and consumers are the base for normal operation of green supply chain. Therefore, the coordination mechanism of them is fundamental. However, diversified goals of members of green supply chain brought barriers for their cooperation. Aiming at the particularity of green supply chain, they proposed a three-level coordination mechanism of business level, motive level and strategy level to analyze the cooperation of members in green supply chain. Li Zhuang-kuo and Liu Xing made a comprehensive evaluation of coordination mechanism of green supply chain and based on AHP method they concluded that a sound coordination relationship between member enterprises in green supply chain can exert positive influence on green supply chain [9]. Based on a survey of North American manufacturers, Vechon and Klassen examined the impact of environmental collaborative activities on manufacturing performance [10]. The influence of collaboration in each direction was empirically assessed for multiple objective and perceptual measures of manufacturing performance using a sample of plants in the package printing industry. Hu Ji-ling, et al., analyzed information sharing and information transfer of members in green supply chain [11]. They explored the factors which impede knowledge transfer in member enterprises and proposed strategies for promoting knowledge transfer in members and further studied the ways for members to transfer knowledge. Wu Shou, et al., pointed out in green supply chain reverse supply chain exhibited good environmental performance and on the other hand it also led to environmental cost. The coordination and apportioning of environmental cost is the key to maintain balance between economic indicators and environmental indicators [12]. Therefore, better dealing with environmental cost becomes the key for members in green supply chain to establish cooperation relationship. Zhao Lin-feng proposed several strategies to improve cooperation satisfaction of member enterprises in green supply chain [13]. Zhang De-hai pointed out that the asymmetry of information in supply chain reduced the synergy effect of cooperative innovation of members [14]. By enhancing the cooperation of members supply chain can realize innovation. On the assumption that the tasks innovative members undertake are complementary, the paper built a multi-agent 
model. The results showed that output performance coefficient, the extent of complentarity of tasks of agents and effort cost parameter are very important factors for cooperative innovation mechanism. Furthermore, suggestions were proposed to restructure the cooperative innovation mechanism of green supply chain by integrating various innovative resources. With the increase of disposal cost of industrial waste and increase of purchasing cost of raw material, lots of attentions have been paid to green supply chain-a kind of cooperation mode of supply chain which aims at the supply relationship of core members of the supply chain [15-27].

From literature review, we can know that the mode of supply chain manufacturers taking the main responsibility in recycling process has become the commonest operation way of green supply chain. However, there is little discussion about optimal government subsidies and taxation policies under the background of supply chain manufacturers based recycling way. Some related researches also did not make further studies on it. Therefore, in green supply chain context, this paper establishes a three-stage dynamic game model consisting of manufacturers, retailers, recyclers and government. Based on the model, this paper analyzes the influence of different governmental economic policies and related variables on social welfare and profits of supply chain members. It intends to provide references for formulation of governmental policies as well as management of members of green supply chain.

\section{Problem Description and Assumptions}

Table 1 shows a typical green supply chain structure. Core manufacturer of supply chain 1 provides industrial waste (such as by-products and residues) produced in production to core manufacturer of supply chain 2 as raw material. Because the production of industrial waste mainly depends on market demand of main products, production of industrial waste is limited. When the quantity of industrial waste provided by supply chain 1 is less than the demand of manufacturers of supply chain 2 , manufacturers of supply chain 2 will choose to cooperate with other industrial waste providers or purchase from common raw material suppliers to complement. The environmental economic policies of green supply chain adopted by government are usually comprised of two parts: 1 . Waste disposal fee collected on products; 2 . Recycling subsidies provided to the third party recyclers according to quantity of recycling. There are three types of interest relationship needing to be coordinated: interest coordination among manufacturers, that between manufacturers and retailers, and that between government and manufacturers.

Table 1. Green Supply Chain Model

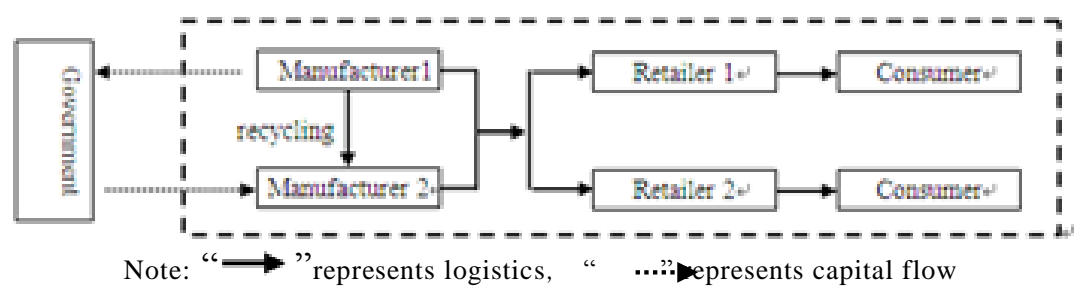

In the operation process of green supply chain: there are two types of material for manufacturer to produce: raw material and renewable material. The cost for manufacturers to use raw material is $C_{n}$ and the cost for manufacturers to use renewable material is $C_{r}$. Suppose manufacturer 1 provides industrial waste to manufacturer 2 and manufacturer 2 can process industrial waste. The quantity of industrial waste manufacturer 1 provides is $x$. The disposal cost of industrial waste is $e$. Unit processing cost is $h$. The demand of manufacturer 2 for industrial waste is $\varpi(\varpi>x)$ and $R(\varpi)$ is 
the unit expected payoffs of waste recycling of manufacturer 2. Suppose manufacturers and retailers in supply chain operate separately and both are in pursuit of maximization of individual interests. Manufacturers first propose the contract and offer wholesale price $W_{i}$ as well as gains sharing ratio $\theta_{i}$. If retailer accepts the offer, he or she will order $q_{i}$ products with price of $W_{i}$. Products are mainly sold to two oligarchic retailers 1 and 2 . Suppose the demand of retailer is $q_{i}$ and price function is $p_{i}=a_{i}-q_{i}-d q_{j}$, where $a_{i}$ denotes size of market of retailer, $d$ denotes influencing factor of demand of retailer $i$ on retailer $j .0<d<1$ and payoff function of retailer $i$ is $U_{i}=p_{i} q_{i}$. Manufacturer 2 is mainly responsible for recycling and reusing. Recycled products can be processed to be renewable material which can be reused by manufacturers. Suppose the fixed cost of recycler is $C_{f}$, recovery rate of product is $t$, difficulty coefficient of product recycling is

$\mu$. Suppose industrial waste disposal fee collected by government is $f$, the optimal recycling subsidy provided to recycler is $s$.

\section{Analysis of Interest Coordination of Member Enterprises in Green Supply Chain}

Based on above assumption, we have the payoff function of manufacturer 1:

$$
\pi_{m 1}=p x+e x-h x
$$

The payoff function of manufacturer 2 is:

$$
\begin{aligned}
& \pi_{m 2}=R(\varpi)-p x-(\varpi-x) t c_{r}-c_{f} \\
& \text { s.t. } \quad R(\varpi)-p x-(\varpi-x) t c_{r}-c_{f} \geq R(t \varpi)-\varpi t c_{r}
\end{aligned}
$$

Equation (3) indicates manufacturer 2 can use common raw material to produce and can also use industrial waste to produce. The necessary condition on reuse of industrial waste is that the utility of using industrial waste to produce is no less than the utility of using common raw material to produce.

Combing equation (1), (2), (3), we can get the equilibrium solution:

$$
\begin{gathered}
p=R(\varpi)-(\varpi-x) t c_{r}+h x-c_{f}-e x / 2 x \\
\pi_{m}=\pi_{m 1}+\pi_{m 2}=p x+e x-h x+R(\varpi)-p x-(\varpi-x) c_{r}-c_{f}
\end{gathered}
$$

Combining equation (1), (2), (4), we find $\pi_{m 1}=\pi_{m 2}$. This indicates manufacturer 2 has the motive to recycle industrial waste only when manufacturers can get the same payoffs, that is, the utility the two manufacturers can get from reusing industrial waste is the same. From equation (4) we can know that the total utility is an increasing function of $x / \varpi$, which indicates with the increase of ability to provide industrial waste, the total utility of reusing industrial waste is getting larger and the total utility reaches the largest when $x / \varpi=1$.

\section{Analysis of Interest Coordination of Manufacturers and Retailers in Green Supply Chain}

We use gain sharing contract to coordinate interests between manufacturers and retailers in green supply chain. At this time, based on maximization of individual interests, manufacturers and retailers can decide the quantity of product $q_{i}$ and sales price. Suppose $\pi_{r i}$ denotes the payoffs the ith retailer can get and it satisfies: 


$$
\pi_{r i}=\theta_{i}\left[q_{i}\left(a_{i}-q_{i}-d q_{j}\right)\right]-\left(w_{i}-c_{i}\right) q_{i}
$$

Suppose $\pi_{m}$ denotes the payoffs manufacturers get and we have:

$$
\pi_{m}=\sum_{i=1}^{2} \pi_{m i}=\sum_{i=1}^{2}\left\{\left(1-\theta_{i}\right)\left[q_{i}\left(a_{i}-q_{i}-d q_{j}\right)\right]+\left(w_{i}-c_{i}\right) q_{i}\right\}
$$

and we have $\pi_{r i}>0, \pi_{m}>0$.

Gain sharing contract can coordinate interests between manufacturers and retailers and based on each other's negotiation power we can decide gain sharing ratio $\theta_{i}$ to realize the allocation of payoffs among members in the supply chain. And the optimal quantity is $q^{0}\left(q_{i}^{0}, q_{j}^{0}\right)$, which can be decided by $\partial \pi_{s} / \partial q_{i}=0$ and $\partial \pi_{s} / \partial q_{j}=0$, where $\pi_{s}$ denotes the total payoffs function of supply chain. It satisfies:

$$
\pi_{s}=\sum_{i=1}^{2} \pi_{s i}=q_{i}\left(a_{i}-q_{i}-d q_{j}\right)-q_{i} c_{i}-q_{i}\left(t c_{r}+(1-t) c_{n}+f\right)
$$

At this time the wholesale price $w_{i}$ provided by manufacturer to retailer i satisfies:

$$
w_{i}=\theta_{i}\left[c_{i}+t c_{r}+(1-t) c_{n}+f+d q_{j}^{0}\right]-c_{i}
$$

Then the payoffs of the ith retailer is

$$
\pi_{r i}\left(q^{0}\right)=\theta_{i}\left[\pi_{s i}\left(q^{0}\right)-q_{i}^{0} d q_{j}^{0}\right]
$$

the payoffs of manufacturers related to retailer i is

$$
\pi_{m}\left(q^{0}\right)=\sum_{i=1}^{2} \pi_{m i}\left(q^{0}\right)=\sum_{i=1}^{2}\left\{\left(1-\theta_{i}\right)\left[\pi_{r i}\left(q^{0}\right)-q_{i}^{0} d q_{j}^{0}\right]+q_{i}^{0} d q_{j}^{0}\right\}
$$

\section{Analysis of Interest Coordination of Manufacturers and Government}

Government adopts the double economic policies which collects industrial waste disposal fee from manufacturer 1 and offers subsidy to manufacturer 2. To maximize social welfare with consideration of budget restriction, government formulates the optimal environmental incentive strategy to decide the optimal industrial waste disposal fee $f$ and recycling subsidy $s$. Total social welfare is equal to the payoffs of manufacturers, retailers and recyclers plus consumer surplus, industrial waste disposal fee and recycling subsidy and deducts the marginal environmental cost $\mathrm{H}$ of final product and lastly plus the marginal environmental payoffs $\mathrm{V}$ of recycling industrial waste. Combining optimal product quantity $q^{0}\left(q_{i}^{0}, q_{j}^{0}\right)$ and total social welfare function, we can calculate optimal recovery rate:

$$
c_{f}=\mu t^{2}
$$

Then,

$$
\pi_{s}=-\mu t^{2}+s \sum_{i=1}^{2} q_{i}^{0} t
$$

From $d \pi_{s} / d t=0$, we can get:

$$
t^{0}=\sum_{i=1}^{2}\left(a_{i}-c_{i}\right) s-2 s\left(c_{n}+f\right) / s\left(c_{r}-c_{n}\right)+\mu(1+d)
$$

Combining equation (13) and total social welfare function, we can get 


$$
\pi_{s w}=\frac{1}{2} \sum_{i=1}^{2}\left(q_{i}^{0}\right)^{2}+\sum_{i=1}^{2} \pi_{r i}+\pi_{m}+\pi_{s}+\left(\sum_{i=1}^{2} q_{i}^{0} f-t^{0} \sum_{i=1}^{2} q_{i}^{0} s\right)-H \sum_{i=1}^{2} q_{i}^{0}+V t^{0} \sum_{i=1}^{2} q_{i}^{0}
$$

Suppose the optimal economic policy of government is $\left(f^{*}, s^{*}\right)$ when total social welfare is largest. To solve the above optimal problem we construct Lagrange function. Then the Kuhn Tucker condition of the optimal problem is that at the optimal point $\left(f^{*}, s^{*}\right)$, there exists $\lambda \geq 0$ which satisfies the following equations:

$$
\left\{\begin{array}{l}
\frac{\partial L\left(f^{*}, s^{*}\right)}{\partial f^{*}}=0 \\
\frac{\partial L\left(f^{*}, s^{*}\right)}{\partial s^{*}}=0 \\
\frac{\partial L\left(f^{*}, s^{*}\right)}{\partial \lambda} \geq 0 \\
\lambda\left[f^{*} \sum_{i=1}^{2} q_{i}^{0}\left(f^{*}, s^{*}\right)-s^{*} t^{0}\left(f^{*}, s^{*}\right)\right]=0
\end{array}\right.
$$

From solution of the equations we can get the optimal industrial waste disposal fee $f^{*}$ and optimal governmental subsidy $s^{*}$.

$$
\begin{gathered}
f^{*}=\frac{2 H\left[\left(c_{n}-c_{r}\right)\left(c_{n}-c_{r}+V\right)-2 \mu(1+d)\right]}{2\left[\left(c_{n}-c_{r}+V\right)^{2}-\mu(2 d+1)\right]}+\frac{\left[V^{2}+\left(c_{n}-c_{r}\right) V+\mu\right]\left[\sum_{i=1}^{2}\left(a_{i}-c_{i}\right)-2 c_{n}\right]}{2\left[\left(c_{n}-c_{r}+V\right)^{2}-\mu(2 d+1)\right]} \\
s^{*}=\frac{2 \mu(1+d)\left(c_{n}-c_{r}+V\right)}{\left(c_{n}-c_{r}+V\right)\left(c_{n}-c_{r}\right)+2 \mu(1+d)}
\end{gathered}
$$

\section{Conclusions}

This paper establishes a three-stage dynamic game model consisting of government, manufacturers and retailers in the context of green supply chain. The results show that:

(1) The price of industrial waste is decided by many factors including supply ability of manufacturers, gains of reuse, price of raw material, processing cost, extra production cost and environmental disposal cost. Given supply ability of manufacturers, the price of industrial waste is the decreasing function of extra reuse cost, price of raw material and environmental disposal cost; And it is the increasing function of reuse gains and processing cost. When extra unit fixed cost of reuse of industrial waste is larger than the unit profit of using common raw material, with the increase of supply ability of manufacturer, the price of industrial waste is increasing. However, when extra unit fixed cost of reuse of industrial waste is less than the unit profit of using common raw material, with the increase of supply ability of manufacturer, the price of industrial waste is decreasing.

(2) Gain sharing contract can realize interest coordination between manufacturers and retailers. Based on each other' s negotiation power, the gain sharing ratio can be decided and extra profits can be allocated among members. If marginal environmental cost parameter decreases, profits of retailers and manufacturers in green supply chain will increase and total social welfare will increase too.

(3) Based on maximization of total social welfare, government can formulate optimal environmental economic policies, that is, collecting industrial waste disposal fee and offering recycler optimal subsidies. If government adopts the double economic policies, 
reducing disposal fee of manufacturers will increase total social welfare and at the same time relieve production burdens of enterprises

Based on above results, we suggest in green supply chain context, government can adopt subsidized and fee collected double economic policies to encourage the third party recyclers to actively participate in recycling business. Furthermore, government can make efforts to improve the environmental awareness of consumers and members of supply chain and take all possible measures to reduce the negative effect of production activities on environment to increase the marginal environmental gains of recycling. We believe by these means the total social welfare can be effectively increased and so do the gains of members of supply chain and eventually realize the sustainable development of green supply chain.

\section{Acknowledgements}

This work is supported by the National Natural Science Foundation of China under Grants No. (71361013, 71462009, 71463020, 71163014);China Postdoctoral Science Foundation under Grants No.(2013M541867).

\section{References}

[1] L. Hai-Yan, D. Bin and L. Shun-Guo, „Economic analysis and countermeasures of construction of manufacturing supply chain", Management World, vol. 7, no. 167, (2009).

[2] K. Green and B. Morton and S. New, "Greening Organizations Purchasing, Consumption and Innovation”, Organization \& Environment, vol. 13, no. 206, (2000).

[3] J. Hall, "Environmental supply chain dynamics", Journal of Cleaner Production, vol. 8, no. 455, (2000).

[4] L. Xin-Ran and L. Guang-Peng, "Analysis of the value of cooperation in green supply chain”, Journal of Dalian University of Technology, vol. 26, no. 29, (2005).

[5] Z. Pi and W. Chun-Xu, "Selection and estimation of partner in the GSC", Value Engineering, vol. 2, no. 44, (2005).

[6] J. Xu-Ping, X. Jian-Pei, H. Jin-Song, "Research of Price-making Decision and Coordination Mechanism in a Green Supply Chain", Journal of Qingdao university, vol. 21, no. 86, (2006).

[7] S. Vachon and R. D. Klassen, "Green project partnership in the supply chain: the case of the package printing industry", Journal of Cleaner Production, vol. 14, no. 661, (2006).

[8] W. Neng-Ming and Y. Tong, "Discussions on coordination mechanism of green supply chain", Enterprise Economy, vol. 5, no. 13, (2005).

[9] L. Zhuang-Kuo, "Study on coordination management of members in green supply chain", China Management Informationization, vol. 11, no. 79, (2008).

[10] S. Vachon and R. D. Klassen, "Environmental management and manufacturing performance: The role of collaboration in the supply chain", International Journal of Production Economics, vol. 111, no. 299, (2008).

[11] H. Ji-Ling, F. Ti-Jun and L. Gao-Xiang, "Study on inter-firm knowledge transfer in green supply chain", Science and Technology Management Research, vol. 2, no. 209, (2008).

[12] W. Juan and W. Wen-Jie, "Study on coordinative apportioning of environmental cost of manufacturing green supply chain", Commercial Research, vol. 3, no. 25, (2009).

[13] Z. Lin-Feng, "How to Raise the Cooperation Satisfaction among Enterprises Based on Green SCM", Logistics Technology, vol. 8, no. 119, (2009).

[14] Z. De-Hai, "Study on multi-agent cooperative innovation mechanism of green supply chain", Science and Technology Management Research, vol. 5, no. 106, (2010).

[15] Y. Chen, R. Simon, C. Reich-Weiser and J. Woo, "Green Supply Chain”, Green Manufacturing, vol. 10, no. $83,(\mathbf{2 0 1 3})$

[16] C. Si-Hua, "The game analysis of negative externality of environmental logistics and government regulation", International Journal of Environment and Pollution, vol. 51, no. 143, (2013).

[17] C. Si-Hua, "A novel culture algorithm and its application in knowledge integration", Information-an international interdisciplinary Journal, vol. 15, no. 4847, (2012).

[18] C. Si-Hua, "Empirical Research on Knowledge Integration Improving Innovation Ability of IT Enterprise-Based on Structural Equation Model”, Information An International Interdisciplinary Journal, vol. 14, no. 753, (2011).

[19] H. Wei, "China's Technology Innovation Strategy from Technology Transfer Perspective", Informationan International Interdisciplinary Journal, vol. 15, no. 4841, (2012).

[20] Q. Zhu, J. Sarkis, J. J. Cordeiro and K. H. Lai, "Firm-level correlates of emergent green supply chain management practices in the Chinese context”, Omega, vol. 36, no. 577, (2008). 
[21] N. Darnall, G. J. Jolley and R. Handfield, "Environmental management systems and green supply chain management: complements for sustainability?", Business Strategy and the Environment, vol. 17, no. 30, (2008).

[22] J. Sarkisa, Q. Zhu and K. H. Lai, "An organizational theoretic review of green supply chain management literature", International Journal of Production Economics, vol. 130, no. 1, (2011).

[23] W. H. Tsai and S. J. Hung, "A fuzzy goal programming approach for green supply chain optimization under activity-based costing and performance evaluation with a value-chain structure", International Journal of Production Research, vol. 47, no. 4991, (2009).

[24] R. Zhao, G. Neighbour, J. J. Han, M. McGuire and P. Deutz, "Using game theory to describe strategy selection for environmental risk and carbon emissions reduction in the green supply chain", Journal of Loss Prevention in the Process Industries, vol. 25, no. 927, (2012).

[25] C. C. Chen, H. S. Shih, H. J. Shyur and K. S. Wu, "A business strategy selection of green supply chain management via an analytic network process", Computers \& Mathematics with Applications, vol. 64, no. 2544, (2012).

[26] A. Verma and A. Gangele, "Investigation with Fuzzy Analytic Hierarchy Process of Green Supply Chain Management in the Pharmaceutical Industry", International Journal of Innovative Technology and Creative Engineering, vol. 2, no. 1, (2012).

[27] S. G. Azevedo and H. V. Cruz Machado, "The influence of green practices on supply chain performance: A case study approach, Transportation research", Part E, Logistics and transportation review, vol. 47, no. 850, (2011).

\section{Authors}

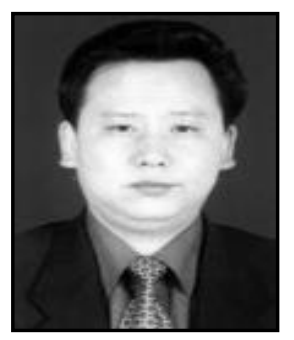

Lu Fu-Cai, is currently a professor and a $\mathrm{PhD}$ supervisor at the Institute of Industrial Economics, Jiangxi University of Finance and Economics, China. He received his PhD from the Graduate School of Chinese Academy of Social Sciences. His research interests include firm theory and human resource management.

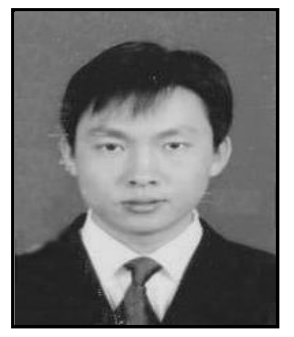

Chen Si-Hua, received his $\mathrm{PhD}$ in management in 2011 form Jiangxi University of Finance and Economics; Currently, he is a researcher at the School of Information Technology in Jiangxi University of Finance and Economics. His research interests include knowledge management and knowledge integration.

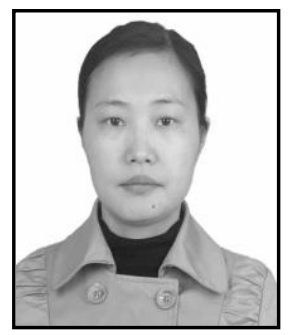

He Wei, received her $\mathrm{PhD}$ in management in 2010 form Jiangxi University of Finance and Economics; Currently, she is a researcher at the School of Business Administration in Jiangxi University of Finance and Economics. Her research interests include human resource management and motivation theory. 